\title{
PERSPECTIVAS METODOLÓGICAS PARA O ENSINO DE MATEMÁTICA: PRÁTICAS NA EDUCAÇÃO BÁSICA
}

\section{METHODOLOGICAL PERSPECTIVES FOR MATH EDUCATION: PRACTICES IN BASIC EDUCATION}

\section{PERSPECTIVAS METODOLÓGICAS PARA LA EDUCACIÓN MATEMÁTICA: PRÁCTICAS EN LA EDUCACIÓN BÁSICA}

\author{
Cristiano dos Santos ${ }^{1}$
}

\begin{abstract}
RESUMO:
O presente artigo abre uma reflexão sobre o Ensino de Matemática, tendo como referência as perspectivas metodológicas das práticas desenvolvidas na educação básica. Tem cunho de relato de experiência, está dividido em quatro seções: Onde nasce as preocupações com as perspectivas metodológicas para o Ensino de Matemática; Visão sobre Ensino de Matemática; Perspectivas metodológicas para o Ensino de Matemática; Minhas práticas metodológicas de ensino na educação básica.
\end{abstract}

Palavras-chave: Perspectivas metodológicas. Ensino de Matemática. Educação básica. Práticas pedagógicas.

\begin{abstract}
This article opens a reflection on the Teaching of Mathematics, having as reference the methodological perspectives of the practices developed in the basic education. It has experience reporting nature, is divided into four sections: Where are concerns about methodological perspectives for teaching mathematics born? Vision on Teaching Mathematics; Methodological perspectives for the Teaching of Mathematics; My teaching methodological practices in basic education.
\end{abstract}

Keywords: Methodological perspectives. Mathematics teaching. Basic education. Pedagogical practices.

\section{RESUMEN:}

Este artículo abre una reflexión sobre la Enseñanza de las Matemáticas, teniendo como referencia las perspectivas metodológicas de las prácticas desarrolladas en la educación básica. Tiene carácter de relato de experiencia, se divide en cuatro secciones: donde nacen las preocupaciones con las perspectivas metodológicas para la Enseñanza de las Matemáticas; Percepción en la Enseñanza de las Matemáticas; Perspectivas metodológicas

1 Mestrando em Matemática -PROFMAT/ UEFS. Especialista em Educação Matemática.Professor da Educação Básica. E-mail: prof.crist@ hotmail.com 
para la Enseñanza de las Matemáticas; Mis prácticas didácticas metodológicas en educación básica.

Palabras clave: Perspectivas metodológicas. Enseñanza de las matemáticas. Educación básica. Prácticas pedagógicas.

\section{Introdução}

Quando se pensa em educação matemática, tem que pensar na diversidade das modalidades de educação (informal, formal, não formal), pensar como ensinar matemática de forma que os estudantes mudem a atitude com relação à disciplina (não gosto, é difícil, não aprendo), para desenvolver o gosto pelo aprender matemática e desencadear um desejo de participação na sociedade.

Desde quando optei pela educação, tenho transitado como docente pelos níveis escolares (educação básica e educação superior) e nas modalidades de ensino (educação de jovens e adultos, educação especial, educação profissional e tecnológica) sendo levado à preocupação de como a Metodologia e Prática do Ensino de Matemática poderá produzir o conhecimento considerando os saberes da sociedade, praticando o dimensionamento filosófico, a ação vinculada aos problemas políticos-sócio-educacionais com o objetivo de encontrar soluções através das práticas pedagógicas, visando realimentar o processo ensino/aprendizagem como um todo e intervindo na realidade concreta. Neste caso, quais seriam as perspectivas metodológicas para o Ensino de Matemática e suas práticas? Abrirei uma reflexão sobre o Ensino de Matemática, tendo como referência as perspectivas metodológicas das práticas que desenvolvo na educação básica ao longo de duas décadas.

O texto está dividido em quatro seções: Onde nasce as preocupações com as perspectivas metodológicas para o Ensino de Matemática; Visão sobre Ensino de Matemática; Perspectivas metodológicas para o Ensino de Matemática; Minhas práticas metodológicas de ensino na educação básica.

\section{Onde nasce as preocupações com as perspectivas metodológicas para o Ensino de Matemática}

Durante a graduação estive engajado em atividades de promoção pedagógica como: representante discente no Colegiado de Matemática com discussões pertinentes a qualidade do curso, a formatação, a avaliação e um novo Projeto Político Pedagógico necessário às mudanças da Licenciatura; envolvimento com os Projetos de Extensão tais como: 
Alfabetização Solidária (Programa de Alfabetização de Jovens e Adultos do Governo Federal), AJA Bahia (Programa de Alfabetização de Jovens e Adultos do Governo da Bahia), PRONERA (Programa de Educação em Áreas de Assentamento do Governo Federal e Movimentos Sociais), Programa Xingó - Área Educação (Programa com áreas temáticas desenvolvido e apoiado pela CHESF - Companhia Hidro Elétrica do São Francisco, CNPq - Conselho Nacional de Desenvolvimento Científico e Tecnológico, SUDENE - Superintendência de Desenvolvimento do Nordeste, Comunidade Solidária, visando o aproveitamento da infraestrutura usada para a construção da UHE - Usina Hidrelétrica de Xingó no rio São Francisco para compartilhar desenvolvimento científico e tecnológico), TRANSE (Transformar a Educação - Programa de Formação de Professores desenvolvido pela Universidade Estadual de Feira de Santana), CAT (Conhecer, Analisar e Transformar a realidade do campo realizado pelo Movimento de Organização Comunitária MOC, em parcerias com a Universidade Estadual de Feira de Santana e prefeituras do Território do Sisal), Educação Profissional Contextualizada (UEFS, 1999) sempre desenvolvendo as atividades de monitor e multiplicador na área de Matemática, na formação para os professores alfabetizadores dos referidos Programas. Ainda na graduação atuei como ministrante de cursos e oficinas na formação de professores da Rede Municipal do de Salvador - BA pela CONSULTEC. Os projetos de extensão que participei, foram um divisor de águas do profissional que me tornei por me propiciar uma diversidade de situações, realidades e reflexões que implicam diretamente no meu trabalho como professor de Matemática.

Com a conclusão da graduação, ingressei na Especialização em Educação Matemática, com a temática monográfica "O professor frente às modernas exigências de Formação: um recorte em Matemática", onde discuto a fragilidade da formação docente diante às condições adversas encontradas em escolas públicas.

Paralelo ao curso de especialização, no Ensino Noturno, nas classes de Aceleração II ( $5^{\mathrm{a}}$ a $8^{\mathrm{a}}$ séries), eu aproveito a minha prática pedagógica com o ensino de números, para trabalhar a ludicidade como proposta de superação das dificuldades e dos obstáculos enfrentados pelos alunos na disciplina Matemática; o que resultou na criação e/ou adaptação de jogos de Matemática, sendo oito deles produzidos e disponibilizados em diversas escolas e nas formações docentes (atualmente disponibilizados no blog (www.profcristianosantos.blogspot.com.br).

Enveredei no Mestrado em Ensino, Filosofia e História das Ciências (convênio UEFS/UFBA, 2005) cursando as disciplinas Tópicos de Modelagem Matemática; Tópicos 
de Filosofia da Matemática e Educação Matemática; Tópicos de Educação Matemática, como aluno especial, objetivando pesquisa na área de Modelagem Matemática. A trajetória de cursar o mestrado como aluno regular foi interrompida pelas questões de oportunidade profissional. Mas, continuo estudando a temática e atualmente (2019) estou na condição de mestrando do Mestrado Profissional em Matemática em Rede Nacional - PROFMAT (CAPES, SBM, IMPA), realizado na Universidade Estadual de Feira de Santana, espero concluir com êxito.

Como docente sempre busco estudar os temas educacionais e participar de cursos que me tornam apto a atuar nos diversos setores da educação formal. Os conhecimentos adquiridos melhoram minha prática e minimizam os conflitos da profissão docente, dentre estes cursos estão: Perspectivas Atuais em História das Ciências; Matemática e Alfabetização; Oficinas Pedagógicas: novas abordagens; Capacitação para alfabetizadores; Curso de Atualização: a Matemática do século XXI; Origami; Hiperatividade; Programa de formação continuada GESTAR I; Curso de atualização em práticas pedagógicas (UNB/SECBA, 2012); Formação de gestores escolares (UNEB, 2008), Formação de Gestores: Gestão Pública (UEFS, 2010)

Em todo o percurso o Ensino de Matemática sempre esteve presente. Sei que sou influenciado pelas várias tendências pedagógicas que permearam ou permeiam o Ensino de Matemática. Contudo, tenho tirado lições de todas para sustentar minha prática e desencadear o gosto, o prazer de aprender matemática na educação básica.

\section{Visão sobre Ensino de Matemática}

Há quem pense que a Matemática e seu ensino estão pautados em única tendência. Mas, Fiorentini (1995) traz as tendências que permearam ou permeiam o ensino de matemática no Brasil: histórico-crítica, formalista clássica, empírico-ativista, formalista moderna, tecnicista, construtivista, socioetnocultural, sociointeracionista-semântica. Isso refere-se à visão macro. Costumeiramente, no campo da Educação Matemática algumas reflexões e contribuições têm sido abordadas como: a etnomatemática, a modelagem, a resolução de problemas, a tecnologia e a filosofia da Educação Matemática para repensar o fazer pedagógico dos professores.

Ao constatar a existência das tendências mencionadas acima levantei uma reflexão sobre o Ensino de Matemática para e na escola, bem como a produção científica na área de conhecimento matemático. Sem me alongar faço menção sobre a tendência histórico-crítica.

Revista Educação e Ciências Sociais (ISSN: 2595-9980), Salvador, v.3, n.4, 2020 
A tendência histórico-crítica concebe a Matemática como algo vivo que se constitui no movimento histórico dos homens, atendendo necessidades sociais concretas. Tem como pressuposto básico que os alunos das classes sociais menos favorecidas, no modo de produção capitalista, devem se apropriar dos conhecimentos matemáticos produzidos historicamente pela humanidade como um dos requisitos fundamentais para a formação de sua cidadania. A questão fundamental está na relação conteúdo x forma do processo de apropriação dos conhecimentos. Nessa relação deve ser explicitado tanto o lógico-histórico, como lógico-matemático, que levaram o homem a produzir aquele conhecimento que está sendo estudado (FIORENTINI, 1995).

Um conceito que a criança elabora desde quando entra na escola e que conserva a sua identidade durante todo o processo de estudo da Matemática Escolar, pode estar ligado ao desenvolvimento de conceitos matemáticos (conceito de número e sua significação aritmética, geométrica e algébrica) e a fundamentação teórica que a sustenta.

Pedagogicamente, numa perspectiva histórica, a questão central da educação escolar é possibilitar aos estudantes o acesso aos conceitos científicos. Sendo assim, o objeto específico do trabalho escolar é o conhecimento científico; sua função específica é a socialização desse conhecimento, é o saber sistematizado (SAVIANI, 2008).

Pode-se inferir que o papel da educação escolar é o desenvolvimento intelectual do estudante, mediado pelos conceitos científicos. Porém, para que o professor possa desempenhar sua função, precisa, necessariamente, conhecer como o ser humano aprende e se desenvolve. E, saber aplicar as melhores metodologias para cada contexto.

Segundo Braguim (2006), pode-se indicar aqui, resumidamente, quatro abordagens metodológicas para o desenvolvimento de aulas no Ensino de Matemática em: (1) Herbart Expositiva Tradicional: Aulas diretivas, onde o professor é o centro das atenções, detentor do conhecimento e os alunos trabalham individualmente através de exercícios. (2) Freinet (1967) e Dewey (1979) - Oficinas: A prática é o foco, a sala de aula torna-se um canteiro de obras e os alunos em grupos buscam o conhecimento através da experiência direcionada pelo professor que procura dar oportunidades para deduções e construções do conhecimento. (3) Ponte (1997), Weiss e Cruz (2001), Ponte e Canavarro (1997), Moran (2003) - Com o Auxílio do Computador: Os alunos conhecem a teoria individualmente na sala fixa (sala de aula que oferece ao professor o quadro como principal recurso para o ensino) e em duplas no Laboratório de Informática a solidificam na construção de um projeto onde podem criar inúmeras opções de aplicação. (4) D’Ambrosio (1996), Floriani (2000), Lopes (2003), Martins (2005), Abrantes (1994) - Projeto Temático: Os alunos em grupos veem a teoria e a

Revista Educação e Ciências Sociais (ISSN: 2595-9980), Salvador, v.3, n.4, 2020 
usam na prática através de um projeto onde aplicam o conhecimento adquirido na busca de uma aprendizagem significativa.

Cabe ao professor conhecer todas as possibilidades e conseguir mesclar de maneira eficaz as abordagens que deem condições de aprendizagem aos estudantes. Quatro abordagens metodológicas do ponto de vista de certos autores, que além de defini-las, as descrevem em termos de possibilidades de sucesso. Essa discussão é utilizada neste texto como referencial teórico.

\section{Perspectivas metodológicas para o Ensino de Matemática}

A metodologia de ensino utilizada em sala de aula é uma das maiores queixas dos estudantes, por não conseguirem relacionar o que aprendem na escola com as suas necessidades diárias, ou seja, não há uma aprendizagem significativa; principalmente, quando se trata da disciplina Matemática que é vista como "vilã” e causa principal das reprovações dos estudantes.

O Ensino de Matemática, frequentemente, é transmitido de modo técnico, teórico e abstrato, apresentado quase sempre sem um relacionamento intencional com os fatos reais e, quando se tem a intenção de superação do irreal, das abstrações, às ilustrações em geral, são artificiais e por muitas vezes, distanciam ainda mais o aprendiz de conceitos mais abstratos.

A mera transmissão de conteúdos matemáticos realizada pelos professores é considerada por alguns autores (FONSECA, 2005; D’AMBROSIO, 1989; ANGELUCCI; et al, 2004; CARDIM, 2011) como um dos motivos da falta de interesse e da consequente evasão escolar por parte dos estudantes que não obtêm sucesso na disciplina. Por conta disso, a qualidade do ensino precisa, urgentemente, ser melhorada e para que isto aconteça é necessário que haja uma mudança na prática pedagógica adotada nas turmas.

Contudo, outros aspectos precisam serem levados em consideração, como: problemas emocionais e de aprendizagem do estudante; afastamento da família dos deveres escolares; competência técnica do professor; inadequação institucional e falta de materiais básicos; questões de política educacional (WEBER, 2013). Mas, não abordarei aqui, pois a questão pedagógica consiste no cerne da discussão e nos relatos que apresentarei mais adiante.

Recentemente, nos últimos vinte anos, eu procuro, visando à melhoria na construção do conhecimento por parte dos estudantes e um melhor desempenho dos mesmos no processo de aprendizagem, ler e discutir sobre a necessidade de adotar novas metodologias de ensino na sala de aula como por exemplo a modelagem matemática (BARBOSA, 2004,

Revista Educação e Ciências Sociais (ISSN: 2595-9980), Salvador, v.3, n.4, 2020 
2003; BASSANEZI, 2002; BIEMBENGUT, 2002; LIMA NETO, 2013), Etnomatemática (D’AMBROSIO, 2002; SANTOS, 2013), resolução de problemas (MIGUEL, MIORIM, 2011; CURY, MOTTA, 2008, FOSSA, GERALDO, 2008), tecnologia da informação e comunicação (TICs) (BORBA, PENTEADO, 2001), jogos e os materiais concretos (BRASIL, 1997), servem como opções de alternativas pedagógicas para o professor tornar as aulas mais motivadoras e assim atender a heterogeneidade existente nas classes.

Compete à escola cumprir com a finalidade educacional prevista em lei no que tange o pleno desenvolvimento do educando. Então, em cumprimento rigoroso ao que propõe a Lei n. 9394/96 "O ensino será ministrado com base nos seguintes princípios: I - igualdade de condições para o acesso e permanência na escola; II - liberdade de aprender, ensinar, pesquisar e divulgar a cultura, o pensamento, a arte e o saber; III - pluralismo de ideias e de concepções pedagógicas; IV - respeito à liberdade e apreço à tolerância", dentre outros.

O pluralismo de ideias e de concepções pedagógicas devem ser o norteador de toda e qualquer ação do professor. É salutar, trazer esses princípios para a formação e a prática pedagógica do professor de Matemática, concedendo-lhes inúmeras possibilidades do fazer pedagógico para que a escolha não fique presa à repetição de fórmulas e explicações unívocas.

Diante exposto acima, agora, enveredo pela exposição, discussão e resultados de algumas práticas que desenvolvo.

\section{Minhas práticas metodológicas de ensino na educação básica}

Nas minhas práticas metodológicas procuro colocar os estudantes como protagonistas. Essa posição é fruto da experiência que vivenciei na graduação dada a postura que eu tinha e entendia a tríade universitária de ensino-pesquisa-extensão onde o estudante se "coloca como protagonista de sua formação técnica - processo de obtenção de competências necessárias à atuação profissional - de uma formação cidadã - processo que lhe permite reconhecer-se como agente de garantia de direitos e deveres e de transformação social” (POLÍTICA NACIONAL DE EXTENSÃO UNIVERSITÁRIA, 2012, p. 50). Essa perspectiva me moveu a ver a Metodologia e Prática do Ensino de Matemática como desafiante, ideia reforçada pelas Diretrizes Curriculares Nacionais para os Cursos de Matemática, Bacharelado e Licenciatura (2001).

É, a proposta das Diretrizes Curriculares Nacionais para os Cursos de Matemática, Bacharelado e Licenciatura (2001) no que se refere às competências e habilidades próprias

Revista Educação e Ciências Sociais (ISSN: 2595-9980), Salvador, v.3, n.4, 2020 
do educador matemático, que me instiga a exercer a docência como exerço. Pois, o licenciado em Matemática deverá ter as capacidades de:

a) elaborar propostas de ensino-aprendizagem de Matemática para a educação básica;

b) analisar, selecionar e produzir materiais didáticos;

c) analisar criticamente propostas curriculares de Matemática para a educação básica;

d) desenvolver estratégias de ensino que favoreçam a criatividade, a autonomia e a flexibilidade do pensamento matemático dos educandos, buscando trabalhar com mais ênfase nos conceitos do que nas técnicas, fórmulas e algoritmos;

e) perceber a prática docente de Matemática como um processo dinâmico, carregado de incertezas e conflitos, um espaço de criação e reflexão, onde novos conhecimentos são gerados e modificados continuamente;

f) contribuir para a realização de projetos coletivos dentro da escola básica.

Para mim é essencial que o professor em sua prática de ensino possibilite ao estudante refletir sobre o contexto social que esse está inserido durante a aquisição dos conhecimentos matemáticos, numa perspectiva de reconhecer que a educação é um agente transformador de sua vida em sociedade e através dela podemos criar um elo de participação nas aulas de Matemática e na sociedade, no local onde se mora.

No entanto, sou desafiado não só pelos estudantes no primeiro momento em que tento colocar em prática as propostas, abaixo relacionadas, sou questionado inicialmente pelos pais e, por alguns colegas que estão presos na sala de aula em uma zona de conforto na qual o modo tradicionalista ainda prevalece, levando os estudantes a verem a Matemática como disciplina difícil, preocupados em dar todo o conteúdo do livro a despeito do entendimento e compreensão do estudante, evitam a aula de forma dialógica onde considerase o saber do estudante, a bagagem de conhecimentos e novidades que o estudante traz consigo, podendo socializar em sala de aula e relacionar os conteúdos; não os instigam, não os provocam para o querer conhecer e saber e perceber que a Matemática é uma ciência viva e em evolução (FREIRE, 1986).

É importante, neste ponto, ressaltar que alguns conceitos trabalhados em Matemática não têm relação direta com situações cotidianas, e precisam buscar nos conceitos já firmados anteriormente uma base mais sólida, daí a importância dos primeiros anos de formação serem trabalhados com maior cuidado e intencionalidade.

Nos anos iniciais o professor de Matemática deve estabelecer o elo entre o conhecimento matemático e o estudante, e transpô-lo para um nível de abstração cada vez maior. Professor e estudante, juntos, de forma dialógica, crítica devem construir o 
conhecimento matemático através da realidade, numa perspectiva de tornar o aprendizado matemático mais significativo, contribuindo assim para a formação de ambas as partes dentro da sociedade. Saliento, também, que antes de tudo o professor deve refletir sobre sua ação; ser conhecedor de sua realidade; refletir sobre sua práxis; conhecer o estudante e sua realidade, sua crença, um pouco de sua história, de sua cultura, mostrar possibilidades de conhecer seu papel diante da sociedade (FREIRE, 1986).

Mediante tudo isso, fundamento minhas práticas, trabalho a Matemática a partir da vivência do/com o estudante, aprendendo e ensinando numa via de mão dupla.

Descreverei a seguir algumas práticas exitosas que buscam estimular o aprendiz a se apropriar do conhecimento matemático através da utilização do diário reflexivo de Matemática, avisos de avaliação, certificação de mérito acadêmico e, na sequência, os resultados obtidos por estudantes do Ensino Fundamental do Centro de Educação Básica da UEFS (CEB/UEFS) e do Colégio da Polícia Militar - CPM Diva Portela (CPM) que quando motivados, superaram suas dificuldades ao ponto de demostrar isso através da participação em eventos universitários, de formação de professor e como ministrantes de oficias de Matemática já a partir do $6^{\circ}$ ano com 11 anos de idade.

\section{PRÁTICA 01 - AVALIAÇÕES E DIÁRIO DE BORDO}

\section{Apresentação}

Visando a necessidade de nós professores fazermos o momento de escuta dos nossos aprendizes, distribuo o início do primeiro e segundo trimestre, o diário reflexivo como parte do processo avaliativo em Matemática nas turmas de $6^{\circ}$ e $7^{\circ}$ anos do Centro de Educação Básica da UEFS, visando o desenvolvimento do hábito de estudar.

Os materiais entregues (diários, avaliações e lista de exercícios) veem personalizados com fotos das turmas obtidas durante atividades lúdicas na primeira semana ou no ano anterior. Os estudantes ficam entusiasmados em especial por verem suas fotos nas capas dos diários. A comunicação com a família é estabelecida pelo uso do diário que, por vezes, solicito as assinaturas dos pais. Este instrumento proporciona o momento de reflexão sobre o que aprende. 


\section{Imagem das avaliações e do Diário de Bordo e ficha de acompanhamento}
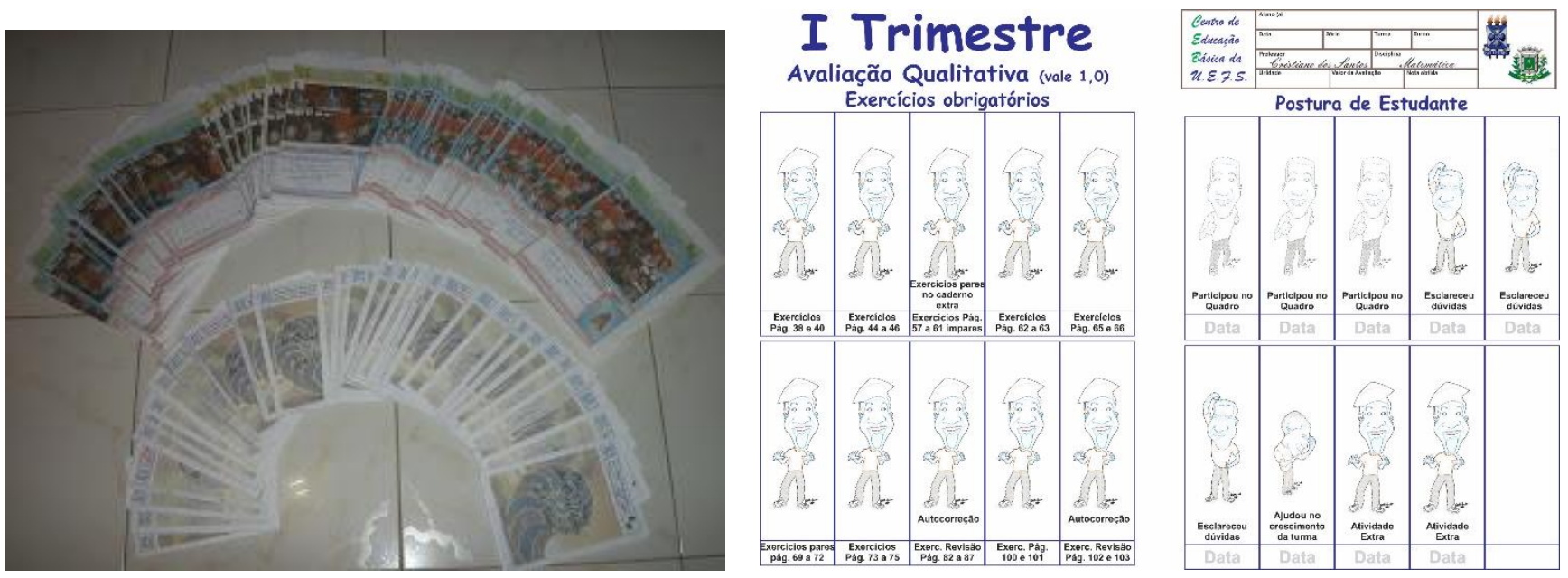

O diário, surgiu como necessidade de fazer um acompanhamento mais de perto das turmas e incentivá-los a escrita e reflexão dos temas abordados na sala de aula, sua impressão sobre o que foi visto e como se sentiu. Há no diário espaço para escrever as metas das notas que desejam alcançar em cada unidade e conselhos a respeito de como tornar-se um bom estudante, assinatura dos pais à medida que avançamos em cada avaliação e explicação de como funcionam os adesivos.

As avaliações têm sempre fotos de atividades que desenvolvemos com cada turma e o(a) estudante pode refazer as questões erradas após colher a assinatura dos pais ou responsável, a cada avaliação refeita, acrescenta 0,5 a sua nota (1/6 do valor da avaliação). Esta prática sinaliza os(as) estudantes e as famílias a interagirem e si ajudarem na caminhada acadêmica.

\section{Justificativa}

Como professor de escola pública, tenho observado uma queixa constante entre os colegas a respeito do grande número de estudantes que não fazem as atividades solicitadas ou quando fazem exercícios, não registram os cálculos, leem e escrevem mal e que durante as aulas se distraem e não prestam atenção as explicações dos professores. Assim nasce a necessidade de oferecer práticas que estimulem os estudantes a desenvolverem uma boa postura estudantil, tendo como foco: leitura e escrita em Matemática, fazer exercícios de Matemática, uma boa participação nas discussões e resolução de questões no quadro, fazer exercícios extras e esclarecer suas dúvidas durante as aulas. 


\section{Objetivos}

Durante a aplicação desta atividade espera-se que o estudante desenvolva suas competências de ler, escrever e resolver problemas de Matemática; tenha responsabilidade com seu aprendizado; desenvolva o gosto pelo aprendizado e pelo aprendizado da Matemática; tenha uma boa postura de estudante e melhore sua nota.

Através da ficha de acompanhamento, verificar os avanços que obtiveram durante a unidade mantendo uma via de contato constante com a família através do diário reflexivo.

Metodologia

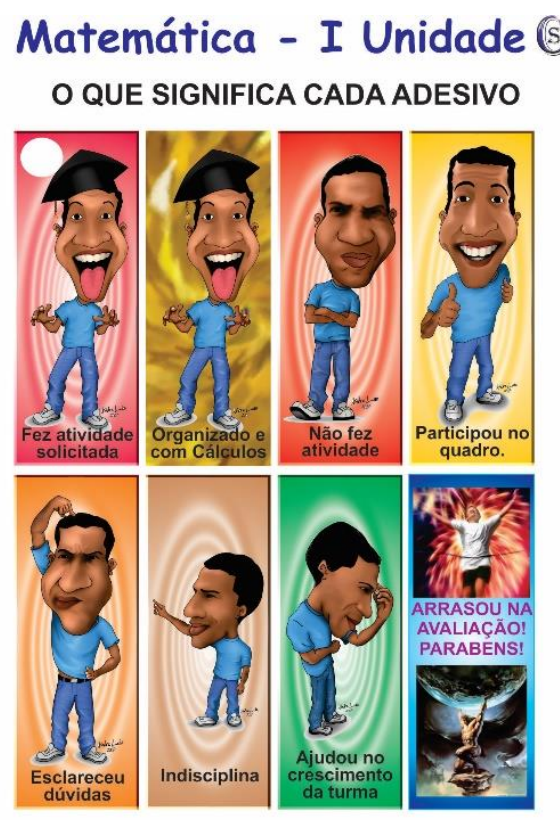

Os adesivos serão distribuídos durante as unidades, visando ao acompanhamento e orientação na construção do saber. Verifique o cartão de acompanhamento e veja como seu(sua) filho(a) está se saido na disciplina.
Foi apresentada aos estudantes uma ficha de acompanhamento (integrante do diário reflexivo) contendo espaços onde seriam colocados adesivos (baseados em minha caricatura), que indicaria o progresso nos estudos em Matemática.

Nesta ficha são indicadas todas as atividades do livro que seriam solicitadas durante o trimestre, já com as páginas e as questões indicadas, espaço para pelo menos três dúvidas, quatro adesivos de participações no quadro, três atividades extras e um para algo extraordinário feito durante a unidade (um cartaz não solicitado, uma pesquisa por conta própria sobre o conteúdo, atuar como monitor durante a aula, entre outros).

A ideia central é ensiná-los a desenvolver bons hábitos de estudo para o aprendizado da Matemática. Essa ideia ganhou forma de diário reflexivo, onde além de conter a ficha de acompanhamento há espaço para escrita e esclarecimento de dúvidas.

No primeiro dia de aula são entregues os diários reflexivos contendo calendário dos dias letivos, espaço para que os estudantes registrassem até 48 aulas de Matemática, orientações do que se espera deles enquanto estudantes, espaço para estabelecimento de metas (notas) para a unidade e a ficha de acompanhamento conforme descrito anteriormente.

$\mathrm{Na}$ ficha de acompanhamento é explicado que para cada passo alcançado, eles recebem um adesivo que representem o histórico deles na disciplina Matemática. A cada exercício solicitado é verificado o caderno do estudante e colado o adesivo correspondente. 
E, durante a entrega das avaliações, aqueles que se saem bem recebem o adesivo de arrasou na avaliação.

Curioso que mesmo nas turmas onde outros colegas tiveram dificuldades, foram poucos os adesivos de indisciplina. Cada estudante pode verificar seu desenvolvimento a medida que a sua cartela é preenchida e é sempre frisado que cada um está escrevendo sua história, portanto, devem evitar comparar suas fichas.

Todos são elogiados à medida que fazem suas tarefas e alguns até mesmo se adiantam escrevendo as perguntas e respostas para poderem receber o adesivo dourado (que representa uma atividade, organizada, com cálculos).

Com a turma fazendo mais exercícios e participando mais no quadro e tirando suas dúvidas fica mais fácil desenvolver os conteúdos, as notas da primeira unidade são superiores a outras turmas.

Algo marcante nesta atividade: os estudantes amam as aulas de Matemática, uma delas até mesmo criou um blog intitulado "Matemática - vale a pena estudar" (http://projetmatematica.blogspot.com.br/ em 2014), o que me deixou muito orgulhoso.

Durante a primeira unidade de 2014, pude identificar e acompanhar os estudantes que deixaram de fazer as tarefas, esses representam cerca de $10 \%$ de todas as minhas turmas, a regra é ter as tarefas feitas no caderno e por conta do adesivo de organizado e com cálculo os estudantes copiam as perguntas e respondem deixando os cálculos no caderno sendo esse um dos maiores ganhos no desenvolvimento da postura de estudante.

\section{Avaliação}

Desde que iniciei com o uso da ficha de acompanhamento, diário reflexivo e envio de aviso de avaliações para os pais assinarem, o rendimento das minhas turmas têm crescido e o gosto pelo estudo da Matemática tem sido evidente na escola e em casa, como elogiam frequentemente os pais dos estudantes.

Esta atividade foi aplicada nas escolas onde atuo, a exemplo do Monsenhor Mario Pessoa em 2012 onde a média da turma de $6^{\circ}$ ano era 3,1 e em 2013 média 4,0; CPM - Diva Portela 2014 média 5,7, ambas da rede estadual de ensino.

Observe por exemplo, o comparativo das médias da $1^{\text {a }}$ unidade letiva das escolas públicas às quais trabalho ou trabalhei com o $6^{\circ}$ ano em 2010, 2012, 2014, 2016 e 2018. 
Tabela 01 - Rendimento do I Trimestre $6^{\circ}$ ano CEB/UEFS

\begin{tabular}{|c|c|}
\hline Ano letivo & CEB/UEFS \\
\hline 2010 & 4,8 \\
\hline 2012 & 5,3 \\
\hline 2014 & 5,9 \\
\hline $2016^{2}$ & 3,9 \\
\hline 2018 & 5,9 \\
\hline
\end{tabular}

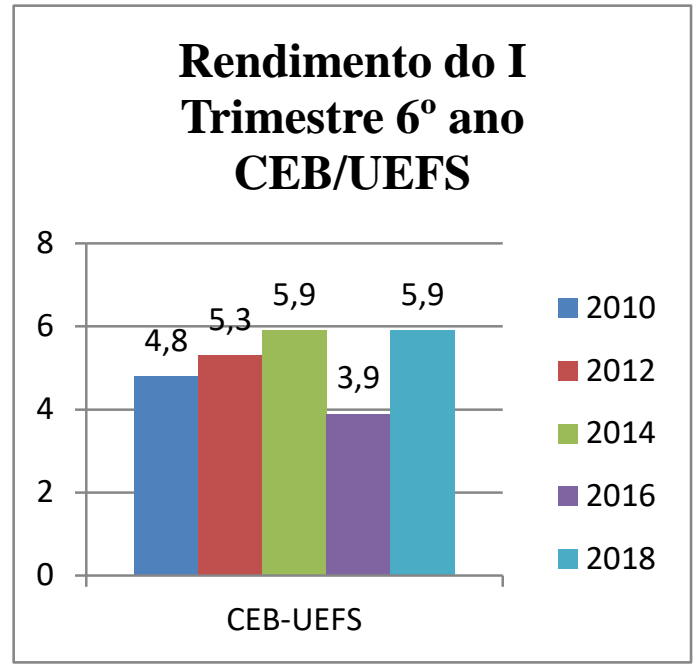

Observamos através do gráfico que o rendimento das turmas está acima dos anos anteriores, o nível de aprendizado dos estudantes está satisfatório e o nível de empolgação deles e dos pais é recompensador.

Algumas das atividades que desenvolvo com os estudantes descrevo no meu blog http://profcristianosantos.blogspot.com.br/ e acredito que junto com o acompanhamento de perto de cada estudante tem motivado o sabor pela disciplina.

\section{Auto avaliação}

Tenho aprendido muito com as estratégias que tenho utilizado atualmente, uma das coisas importantes é ouvir mais os sentimentos e angústias de meus estudantes. As dúvidas que agora estão me enviando por escrito (criei um papel de carta para essa comunicação) apontam para a minha necessidade de me reinventar.

No Centro de Educação Básica da UEFS (CEB-UEFS) trabalho desde 2003 e procuro ser uma referência para os estudantes, pais e colegas, muitos deles preferindo as minhas turmas para estudar.

\section{PRÁTICA 02 - AVISO DE AVALIAÇÃO}

Uma prática que vem dando certo é o aviso de avaliação, que consiste em um resumo do que foi e não foi visto durante quinze a vinte dias que antecederam cada avaliação. Este

\footnotetext{
${ }^{2}$ Neste ano a greve de professores a rede municipal incidiu no início dos trabalhos e atrelado a isso, a pouca adesão na entrega dos diários, apenas 29 estudantes (39\%) entregaram. Outro ponto importante foi que neste ano $58 \%$ dos estudantes não eram oriundos do fundamental do CEB/UEFS.
}

Revista Educação e Ciências Sociais (ISSN: 2595-9980), Salvador, v.3, n.4, 2020 
aviso segue para casa já colado no caderno do aluno e deve ser assinado pelos responsáveis antes e após cada avaliação, só assim o aluno terá direito a refazer as questões que errou na avaliação acrescentando até meio ponto a sua nota da unidade.

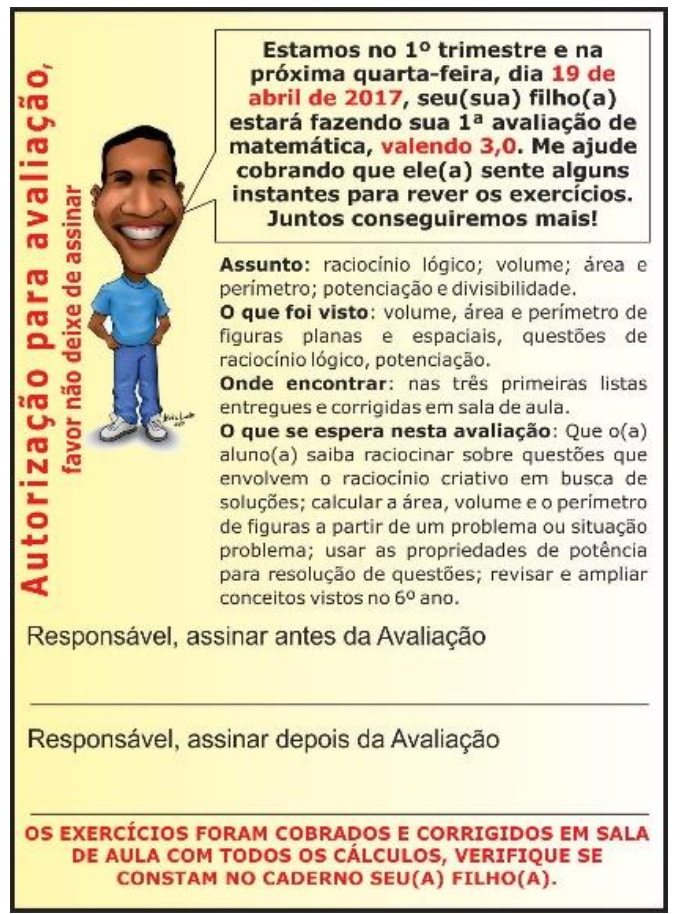

$\mathrm{O}$ intuito na verdade é repensar o erro e ao mesmo tempo manter a família acompanhando o desenvolvimento do estudante, já que é uma reclamação constante de muitos de nós educadores que a família se afastou do processo educativo ou encontra dificuldades em saber como fazer para estar ciente do que está sendo cobrado e o que se espera a cada fase das unidades letivas.

A formatação dos avisos é feita de modo que caibam 4 avisos em uma folha A4 e cada estudante cola um aviso em seu caderno.

O mais difícil é fazer os primeiros avisos, já que nos remete a refletir o objetivo das avaliações com antecedência e informar o(a) estudante destes objetivos.

Há uma participação de mais de $80 \%$ dos pais em acompanhar seus filhos através desta ferramenta de comunicação, alguns ainda procuram de última hora o que vai cair na avaliação, mesmo tendo este material em mãos, o que evidencia desleixo do estudante e dos pais. Isso é constatado no grupo do whatsapp ("Dúvidas de Matemática"3) que criei no intuito e esclarecer dúvidas dos estudantes e responsáveis.

O modelo de aviso é como na figura acima, acredito manter os alunos muito interessados e dispostos ao aprendizado e busco incessantemente a parceria da família na vida estudantil do estudante em minhas turmas.

\section{PRÁTICA 03 - TORNEIO DE TABUADA}

Desde o ano letivo de 2009 tenho trabalhado com estudantes do Fundamental II (iniciando no $6^{\circ}$ ano) com o Torneio de Tabuada, que é dividido em 3 etapas: a primeira conta com a participação de todos os estudantes das turmas nos cinco a dez minutos finais da última aula da semana. É feita uma grande roda e sorteado um produto que o aluno da vez tem que responder sem repetir a tabuada sorteada, caso erre ou demore na resposta, o

\footnotetext{
${ }^{3}$ Em 2019 chegou a ter 183 membros entre pais e estudantes, dois professores e a coordenadora do CPM- Diva Portela. Considero a experiência enriquecedora.
} 
próximo estudante pode responder e o que errou sai da roda, procedemos assim até ficar um estudante (as vezes mais estudantes devido a chegada do final da aula, e também vai ficando cada vez mais difícil eles errarem). Os que conseguem ficar no final da aula ganham um pequeno adesivo de uma coroa que ele/ela cola no diário até atingir o total de quatro coroas, ficando assim classificado para a final do torneio de sua turma (anteriormente usava tabuada impressa com tempo de três minutos para responder 30 produtos ou quocientes e os estudantes trocavam suas folhas entre si e corrigiam um do outro, somavam os pontos e me entregavam).

A segunda etapa é o enfretamento dos classificados no final do trimestre letivo, primeiro meninas e meninos separados para termos a definição da Rainha e do Rei da Tabuada e em seguida o enfrentamento do Rei e da Rainha para definirmos se na sala impera o patriarcado ou o matriarcado (o matriarcado tem sido recorrente nas turmas) Todos os classificados garantem 0,3 na média final, sendo que a terceira, segunda e primeira pessoa mais bem colocado garantem cinco, sete ou dez décimos extra na unidade em que ocorre o torneio. (Atualmente faço por semestre visando redução de custos).

A terceira etapa é o enfrentamento dos Reis e Rainhas das turmas. Quando possível faço no pátio ou auditório com direito a torcida silenciosa. Nesta etapa normalmente tenho conseguido premiações com o comércio local e/ou compro pequenos mimos para os ganhadores (camisas com logomarca do torneio, coroa, brincos com coroas, modelos de boneco em papercraft, entre outros). Nesta etapa, o estudante pode escolher um colega que necessita de até um ponto para atingir a média da unidade e estudarem juntos, pois caso o Rei ou Rainha erre ou se confunda, esse colega pode ajuda-lo uma vez para que ele/ela continue no torneio.

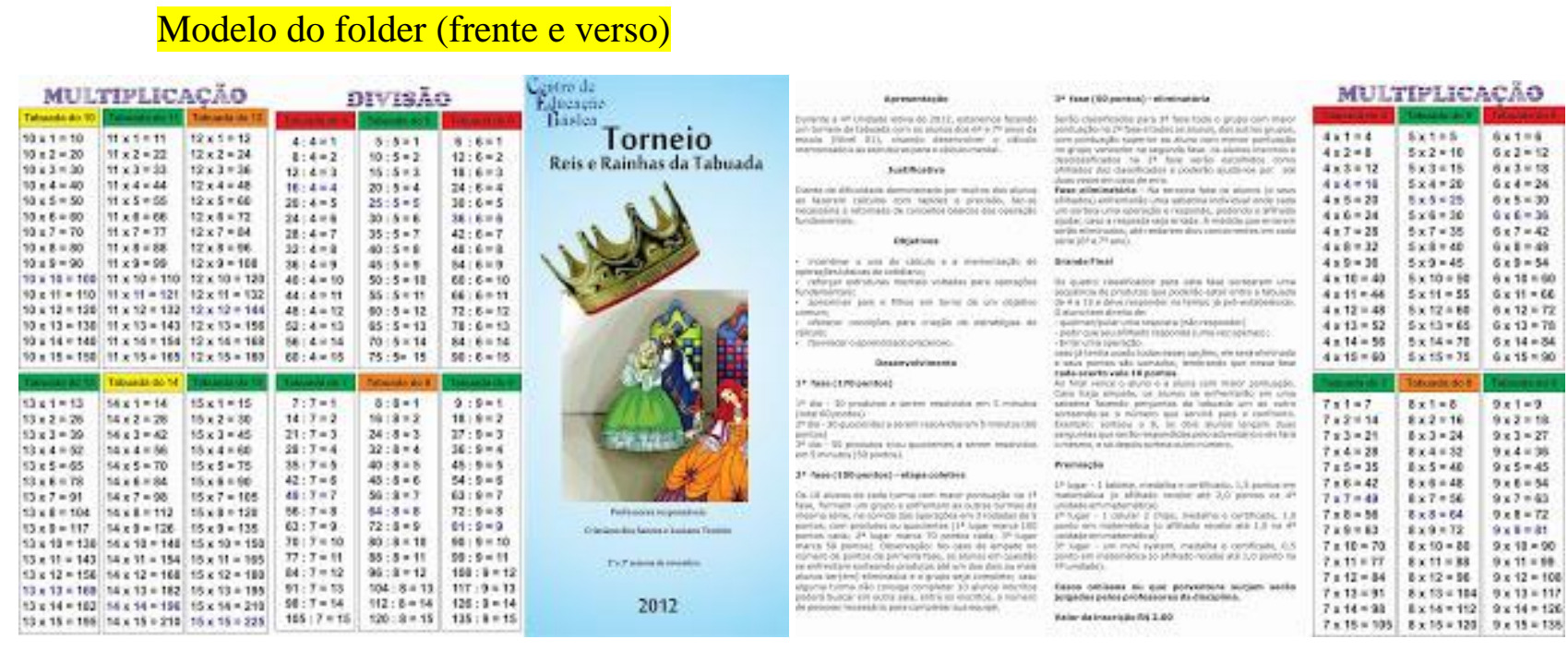

Revista Educação e Ciências Sociais (ISSN: 2595-9980), Salvador, v.3, n.4, 2020 
Criei algumas apresentações PowerPoint (tipo pps, automáticos) que são projetadas com o auxílio do datashow e que os (as) estudantes precisam responder no tempo determinado na apresentação (seis segundos).

Desde 2009 os resultados do torneio e a demonstração de cálculo mental feita pelos finalistas têm me surpreendido. Nas últimas edições, tive que ampliar a tabuada de multiplicar até a tabuada do dezenove e incluir um cronometro de xadrez para definir o ganhador.

Um outro fator a destacar é a participação daqueles que não são tão bons em matemática, mas se saem bem na tabuada, o que tem ajudado a criar gosto pela disciplina.

\section{PRÁTICA 04 - CERTIFICADO DE MÉRITO ACADÊMICO}

A cada semestre, faço o levantamento de quais estudantes conseguiram demonstrar uma postura estudantil que serve de inspiração para seus colegas. O diário reflexivo é muito importante neste momento já que os adesivos colocados durante os trimestres ajudam na definição dos mesmos. Elaborei um modelo de certificado que é entregue a esses/as estudantes preferencialmente na presença da direção e/ou coordenação da escola nas reunião de pais e mestres (maioria das vezes) ou na sala de aula.
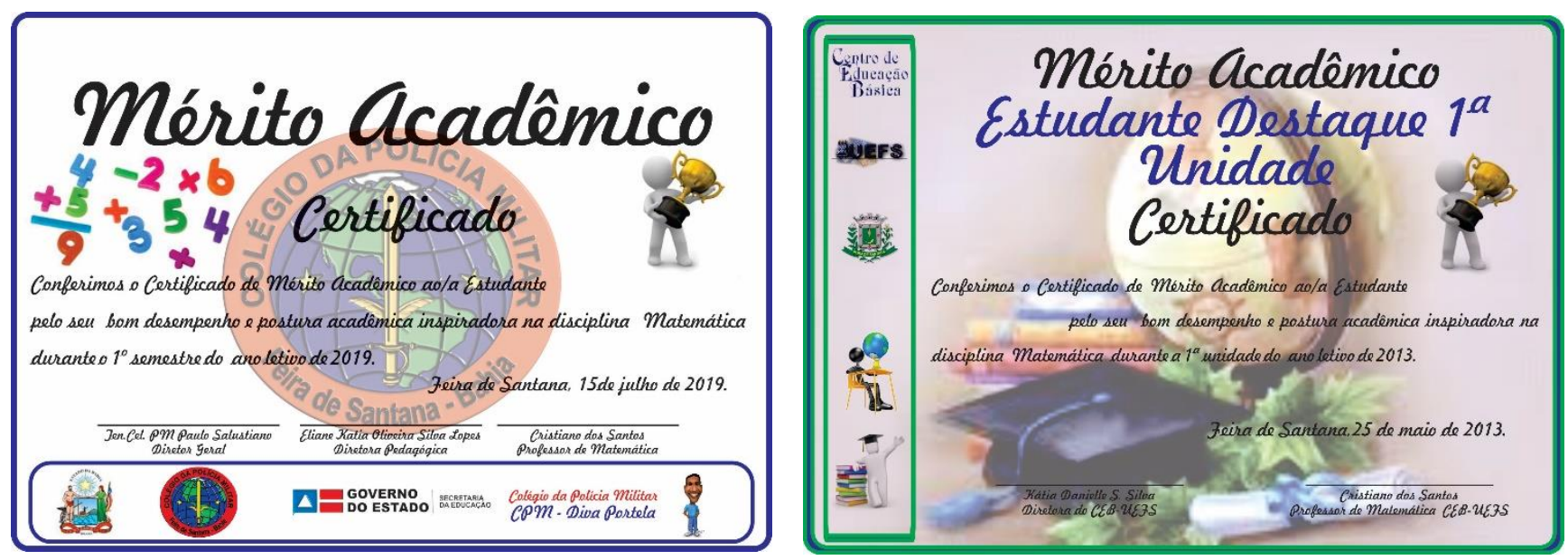

Modelos de certificados de Mérito Acadêmico

Um aspecto importante é que a média final em Matemática nas unidades é importante, porém a atitude e postura estudantil é definitiva para receber o certificado. Em outras palavras, recebe o certificado de mérito acadêmico aquele/a que demostrou empenho em aprender, venceu o receio de participar no quadro, ajudou a turma a crescer, mesmo que 
sua média não esteja entre as melhores da sala, entendendo que naquele momento foi o máximo alcançado por aquele/a estudante.

\section{PRÁTICA 05 - ATIVIDADES QUE EXPLORAM OUTRAS COMPETÊNCIAS}

A partir daqui descrevo alguns dos estímulos didáticos que utilizo nas turmas de $6^{\circ} \mathrm{e}$ $7^{\circ}$ anos e como elas influenciam nas produções feitas com/pelos estudantes e suas participações em eventos e como ministrantes de oficinas para estudantes de outras escolas, estudantes universitários do Curso de Matemática e para professores da rede municipal de Feira de Santana.

Ao mesmo tempo que os estudantes apendem nas minhas aulas de Matemática, busco motivá-los à investigações pessoais de leitura (como exemplo, abaixo as assinaturas no livro "O diabo dos Números" que circula entre os estudantes desde 2012) a cada romance
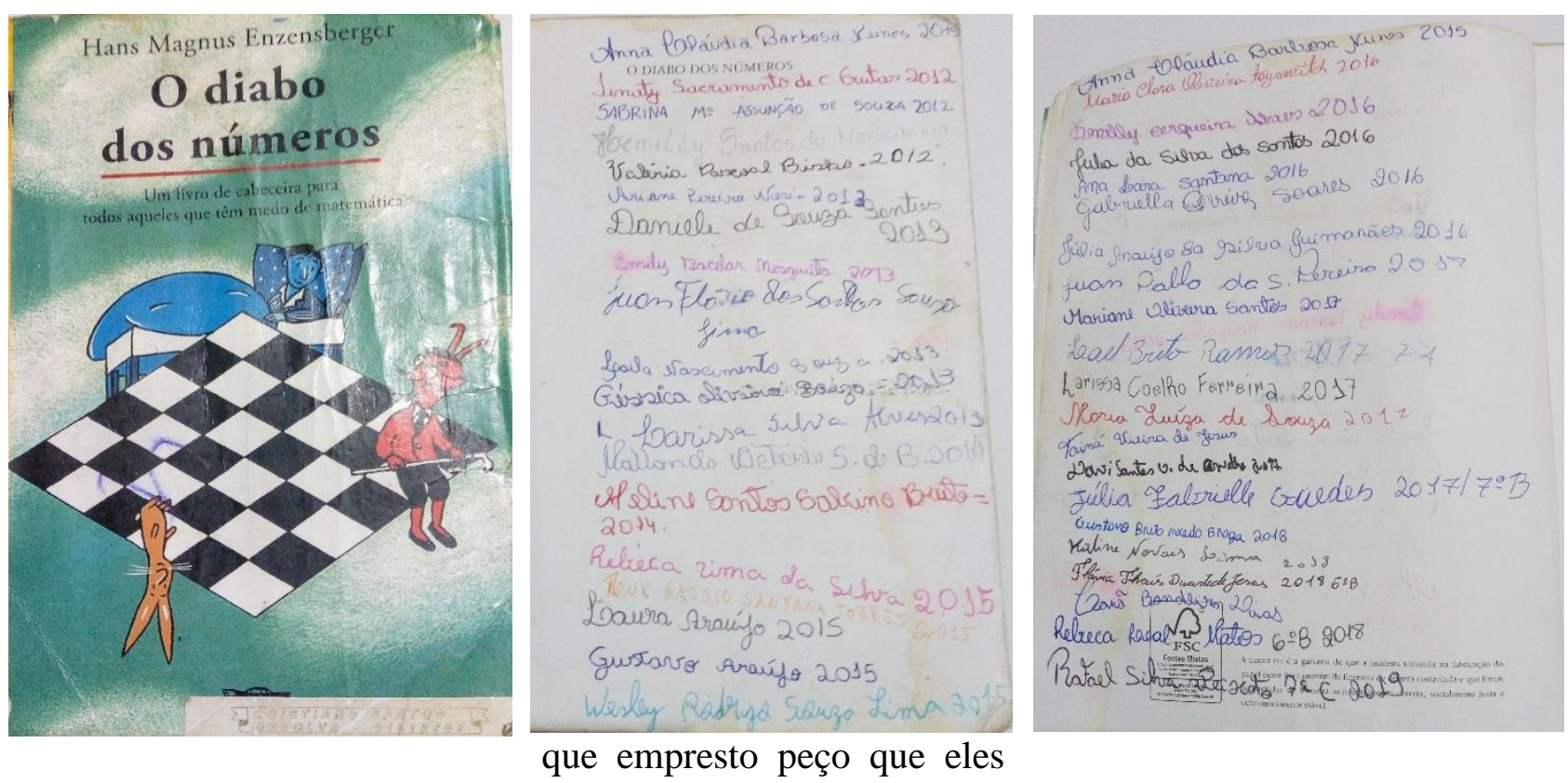

assinem na contracapa para dar uma história própria à aquele exemplar.

Motivos através de aulões onde todas as turmas são convidadas a participarem numa sessão tira dúvidas antes das avaliações, essa atividade reune em média mais de $80 \%$ dos estudantes, alguns chegam a ficar zangados com o pais quando não podem ir. Neste sentido, uma dificuldade é o espaço para reunir tantos estudantes com qualidade de aúdio e conforto climático dentro do espaço escolar.

Os jogos e atividades lúdicas são partes fundamentais para desenvolver sabor pelo aprendizado. Jogos como: Tabuada viva (corrida dos números), quebra-cabeças com 
multiplicação, frações e números inteiros, matix, entre outros são inseridos a cada trimestre letivo para introduzir ou fixar o conteúdo estudado. Os estudantes são convidados a ensinarem essas atividades fora da escola para estudantes de séries igual a deles como troca de experiências e preparação para outras apresentações. Alguns desses jogos disponibilizo mais detalhado em meu blog https://profcristianosantos.blogspot.com/.

A construção de horta e paisagismos tem sido um projeto fomentado por mim e acontece alternado entre os anos letivos do CEB. Fizemos um projeto interdisciplinar para discutirmos meio ambiente e reutilização de materiais de díficil decomposição na natureza. Assim, usamos pneus velhos para formar o jardim da escola. Aliamos desta forma matemática e arte e construimos o jardim de pneus. O objetivo era trabalhar formas geométricas e sistema métrico decimal, tendo o jardim como desencadeador dessas discussões.

Os materiais necessários foram: 81 pneus velhos de diversos tamanhos, tinta acrílica, pincéis, rolinhos, aguarraz, estopa, arame, terra vegetal, plantas, enxada, cavador, picareta, pá.

Esta atividade foi desenvolvida no mês de agosto de 2013, com 95 estudantes do $7^{\circ}$ ano trabalhando voluntariamente para embelezar a escola. Como o chamado foi para voluntariado, a princípio eu esperava menos estudantes, e foi com grata surpresa a chegada de estudantes do turno oposto junto com mães e pais, as professoras Maria do Carmo (Português), Zhara (História), Irenildes (Artes) e os funcionários que deram a maior força no serviço pesado.

Dias antes à construção do jardim, trabalhei com alguns estudantes o sistema métrico utilizando trenas e fitas métricas para tirar medidas dos espaços da escola onde colocaríamos o jardim (este trabalho ainda terá continuidade), noções de paralelismo e perpendicularismo anotamos e passamos para a segunda fase que foi a motivação para o bem comum e a campanha lixo zero.

Sobre grupo de estudos, transcrevo aqui um relato de experiências produzido por mim e estudantes da $8^{\mathrm{a}}$ série ( $9^{\circ}$ ano do fundamental) e que foi apresentado na III Semana de Alfabetização, Leitura e Escrita (SALE), "Fracasso Escolar ou Situação de Fracasso Escolar?", na UNEB Campus de Serrinha, realizada no período de 15 a 17 de setembro de 2005, p. $11-12^{4}$.

\footnotetext{
${ }^{4}$ Caderno de resumos, oficinas e textos. III Semana de Alfabetização, Leitura e Fracasso Escolar ou Situação de Fracasso Escolar, 15-17 setembro de 2005; organização Selma dos Santos; coordenação geral: Ana Cristina Silva Oliveira Pereira. Salvador: EDUNEB, 2005. 120 p. il.
} 


\section{Relato - Grupo de Estudos vencendo o fracasso escolar}

Cristiano dos Santos, Nayá Bastos Santos Lôbo, Sâmila Gomes Santos, Laidson Saturnino S. Santos.

\section{Resumo}

O presente trabalho apresenta em linhas gerais o desenvolvimento do trabalho realizado pelo Grupo de Estudos e Pesquisa em Ciências Exatas e da Natureza (GEPCEN) com alunos da escola pública do Ensino Fundamental de $5^{\text {a a }} 8^{\text {a }}$ séries, com o objetivo de promover uma relação amistosa e prazerosa com o conhecimento através da promoção estudos e pesquisa para adolescentes na faixa etária de 10 a 15 anos de idade. O trabalho vem sendo desenvolvido ao longo de dois anos (julho de 2003 a agosto de 2005). Enfoca a necessidade de criar condições para que os alunos possam explorar o seu potencial através da valorização de ideias, do compromisso com o conhecimento e da redescoberta do prazer de descobrir, utilizando-se de leituras diversas desde temas acadêmicos até literatura de autores nacionais e internacionais. A perspectiva inicial era de que o GEPCEN estudasse apenas temas matemáticos ou afins, porém, hoje estudamos temas relacionados a diversas áreas e idealizamos eventos, como o I Encontro dos Saberes (I ENSAB) que reuniu 21 cursos em diversas áreas no CEB-UEFS durante uma semana e que, em outubro de 2005 terá sua segunda edição. O GEPCEN tem como uma de suas características ajudar seus membros a sair do processo de analfabetismo matemático e científico pelo qual vem passando a escola. São designados temas de livre escolha para pesquisa; publicamos o folhetim do GEPCEN com produção dos alunos; promovemos cursos e oficinas de matemática para alunos de $1^{\mathrm{a}}$ a $4^{\mathrm{a}}$ séries de escolas públicas. Dos teóricos estudados tivemos contato com a teoria de Piaget na construção de oficinas para os alunos da $4^{a}$ série, onde através do texto de Constance Kamii puderam ler e vivenciar algumas das atividades que exploram a capacidade de pensar matematicamente do aluno e pô-las em prática. No Decorrer de dois anos nossos alunos obtiveram uma relação melhor com o conhecimento matemático, fato demonstrado não só pelas notas na disciplina mais também pela atitude melhorada e uma boa relação com outras áreas do conhecimento. Houve um maior envolvimento nas atividades do colégio, maior número de leituras chegando a uma média de 10 romances/ano sendo que os mesmos não eram requisito de nenhuma disciplina. Há um entusiasmo crescente na participação de eventos acadêmicos culminando mais recentemente na apresentação por parte dos membros do grupo de um relato de experiências na Faculdade Jorge Amado durante o Encontro Baiano de Educação Matemática (2005). Acreditamos que a participação no GEPCEN tenha dado aos alunos que o integrara uma leitura de mundo mais solidária ao discutir cidadania, ética, ciência, construção do saber, história das ciências entre outros temas e acreditamos que servirá como bom suporte teórico na construção de uma profissionalização futura.

Palavras-chave: Pesquisa. Conhecimento. Grupo de estudo.

Outra atividade estimulada é a monitoria, os estudantes auxiliam os colegas na própria sala; o estudante monitor senta-se ao lado do colega que está precisando de ajuda e o orienta nas tarefas.

Mais recentemente no CPM - Diva Portela as estudantes do $6^{\circ}$ ano D, deram um show de acompanhamento aos colegas. Me enviaram listas de exercícios perguntando se poderiam usar para orientar seu apadrinhado e alguns desses estudantes começaram a ter um outro ritmo, outros não gostaram de serem cobrados tão de perto, mas o efeito foi positivo para a maioria. Os monitores não recebem nenhum incentivo de nota, são voluntários, sendo que três (todas com 11 anos e mais 9 estudantes do CEB/UEFS) participaram no I Seminário Interno do Programa Residência Pedagógica - Matemática UEFS, na condição de 
ministrante da Oficina de Matemática apresentando uma discussão levantada através de um texto produzido de maneira espontânea pela estudante Priscila da Silva Gomes intitulado "Para resolver o caso dos jovens desinteressados em Matemática" e após explanarem a temática, apresentaram uma das atividades que vivenciaram nas minhas aulas para estudantes do curso de Licenciatura em Matemática da UEFS.

A participação em elaborar, organizar e ministrar oficinas é algo que incentivo a todos os estudantes desde minhas primeiras experiências com o ensino diurno em 2000 até o presente momento. A recompensa colocada para todos/as é sempre a experiência única de atuar em espaços acadêmicos diversos; e sempre friso o caráter não obrigatório, tanto para os estudantes como para os pais, que fica incumbidos de levar e buscar seus filhos das dependências onde ocorrerão os eventos.

É sempre fortalecida a ideia de que eles/elas falaram de tema que já dominam e que eu estarei presente para socorrer caso o nervosismo tente atrapalhar. Daí temos mestres de cerimônia, para incluir aqueles mais tímidos ou que tenham vontade de participar mas não têm tema de estudo específico, ministrantes de atividades lúdicas de abertura, durante o evento e para finalizar, ministrante de temas de Matemática mais complexos: constante de Kaprekar, algoritmo euclidiano para extração e raízes quadradas, álgebra, entre outros).

Essa visão culminou com a produção do projeto de extensão universitária “Troca de Saberes", abaixo descrevo parte do projeto: O evento intitulado "Troca de Saberes: o protagonismo da Educação Básica", consiste em uma ação no campo da Extensão Acadêmica a partir de um Workshop produzido pelos estudantes do componente curricular EDU245 - Didática M 2018.2, cuja formatação tem um caráter inusitado e importante, pelo fato de ser protagonizado por estudantes do Ensino Fundamental II ( $6^{\circ}$ ano fundamental) do Centro de Educação Básica da UEFS e do Ensino Médio do Colégio Estadual Governador Luiz Viana Filho, sob a orientação da Professora Márcia Suely de Oliveira Araújo, via UEFS; e minha. Esta é uma proposta inovadora que torna possível a abertura para infinitas possibilidades de troca de saberes nas mais diversas áreas do conhecimento. Bem como, coloca a UEFS em um status importante de acolhimento ao Nível Básico, para o qual as licenciaturas se propõem em formar professores a fim de ali atuarem.

Este Workshop tem a relevância de trazer a Escola Básica para dentro do Campus Acadêmico da UEFS, de forma que as estudantes do Ensino Fundamental II que adentraram este espaço realizando uma atividade em que elas são as "professoras". Ou seja, a turma de Didática em Matemática organizou o espaço e o tempo de aula para se posicionarem como educandos. Isto significa que, no sentido em que no chão da escola, as estudantes do ensino

Revista Educação e Ciências Sociais (ISSN: 2595-9980), Salvador, v.3, n.4, 2020 
fundamental programaram as atividades de ensino da matemática, sob a minha orientação, para serem realizadas com os estudantes da graduação em Matemática/UEFS. Em contrapartida, os estudantes da graduação em Matemática apresentaram para os pares da Educação Básica, questões interessantes sobre a Graduação em Matemática na UEFS. Nesse sentido, a troca de saberes, que comumente parte de graduandos para os educandos de nível básico, ocorreu como uma via de mão dupla. Contudo, houve um destaque significativo à ação protagonizadora da Educação Básica no Ensino Superior no Workshop.

Deste evento, os/as estudantes ainda apresentaram oficinas com temas variados para os professores da Rede Municipal de Educação em 2019 (cinco estudantes do $6^{\circ}$ ano do CPM e dez estudantes do $7^{\circ}$ ano do CEB) todos voluntários e vencendo o desafio de falar em público sobre Matemática para os professores.

Os estudantes do $7^{\circ}$ ano ainda participaram do I ENDOCE (Encontro Docente sobre Currículo Escolar do $6^{\circ}$ ao $9^{\circ}$ ano - SEDUC Feira de Santana), mesmo sem minha presença, apresentaram relato de experiência durante o evento e mostraram de forma significativa que tipo de Matemática estavam aprendendo.

Para atender a todos da melhor forma, as escolas que trabalho têm seus projetos políticos pedagógicos a partir de uma gestão democrática, com intuito de requerer uma política coletiva visando a melhoria na educação. As escolas buscam reformular seus espaços e rotinas aperfeiçoando suas atividades extracurriculares para o bom aproveitamento de todos.

Um dos locais que trabalho é o Centro de Educação Básica - CEB que tem inserido estudantes com necessidades educativas especiais através da tecnologia assistiva. A tecnologia assistiva é uma estratégia ou um recurso utilizado para possibilitar a execução de uma atividade pretendida ou necessária a uma pessoa com deficiência. Na perspectiva da Educação Inclusiva a tecnologia assistiva favorece a participação do estudante com deficiência em diversas atividades escolares ligadas aos objetivos educacionais comuns. Não poderia ser diferente a ação do professor de Matemática.

Para os estudantes com necessidades especiais tenho adaptado algumas atividades, a exemplo: Baralho com representação de números e sistemas numéricos (ver imagem na página 164), visando ajudar um estudante com síndrome de Down a perceber a relação entre os sistemas de numeração e disco com ângulos móvel, para estudar ângulos. 


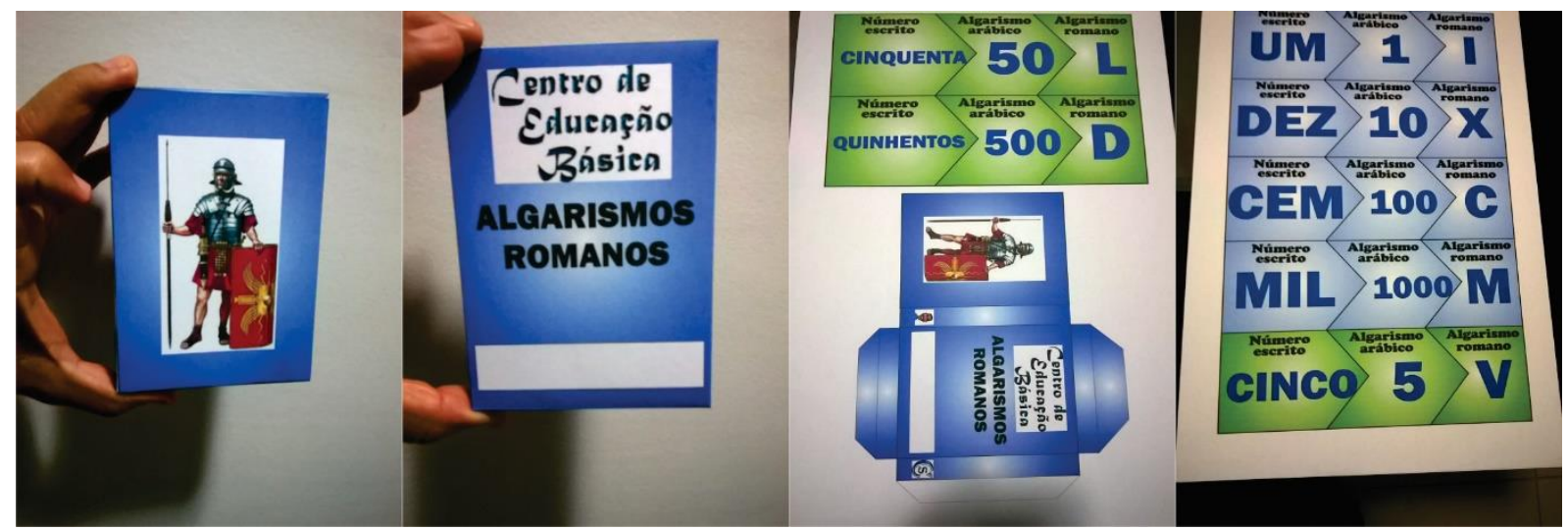

\section{Considerações finais}

Observo que ao possibilitar propostas que motivem as buscas pessoais, os estudantes, têm correspondido de forma significativa e até mesmo superado a expectativa. Dentre os breves relatos que foram feitos aqui, vemos que desde o $6^{\circ}$ ano do Ensino Fundamental, os estudantes mais motivados aceitam os desafios impostos e auto impostos, com seriedade e desenvolvem potencial para além da série cursada.

Em 2019 encontrei uma ex-estudante do primeiro grupo de estudos do CEB/UEFS (Amanda Maria, aluna participante do GEPCEN, apresentou seu primeiro relato de experiências aos 14 anos, num evento regional em Educação Matemática) que fez questão de mostrar seu memorial para inscrição no Doutorado em Saúde Coletiva UEFS. Nele ela descrevia que seu contato com a pesquisa começa no ensino fundamental através da participação das atividades do grupo de estudos que ela havia participado há cerca de 14 anos atrás.

Como ela, muitos dos outros estudantes que vivenciaram o estudo de uma Matemática mais divertida, próxima a sua realidade desafiante e, ainda assim, igualmente complexa trazem a mesma marca: Estudar Matemática é muito bom! Não é fácil, mas ainda assim é empolgante. E quando vejo os estudantes ansiando pela aula de Matemática, sei que estou num bom caminho na minha prática profissional, e espero que essas experiências possam ajudar outros na sua busca de construir sua própria identidade profissional. Façam acontecer na sala de vocês, existem muitas mentes ansiosas pela chance de ter alguém que acredite em seu potencial para despertar. 


\section{Referências}

ANGELUCCI, Carla Biancha; KALMUS, Jaqueline; PAPARELLI, Renata; PATTO, Maria Helena Souza. O estado da arte da pesquisa sobre o fracasso escolar (1991-2002): um estudo introdutório. São Paulo,V.30, jan/abr.2004.

BARBOSA, J. C. Modelagem Matemática: O que é? Por que? Como? In: Veritati, n. 4, p. 73- 80, 2004.

BARBOSA, Jonei Cerqueira. Modelagem Matemática na sala de aula.In: Perspectiva, Erechim (RS), v. 27, n. 98, p. 65-74, junho/2003.

BASSANEZI, Rodney Carlos. Modelagem matemática - um método científico de pesquisa ou uma estratégia de ensino e aprendizagem? In: BASSANEZI, Rodney Carlos. Ensinoaprendizagem com modelagem matemática: uma nova estratégia. São Paulo: Contexto, 2002. p. 15-41.

BIEMBENGUT, Maria Salett; HEIN, Nelson. Modelagem matemática no ensino. São Paulo: Contexto, 2000.

BORBA, M. C.; PENTEADO, M. G. Informática e educação matemática. Belo Horizonte: Autêntica, 2001.

BRAGUIM, Ronaldo Antonio. Abordagens metodológicas no ensino da matemática: perímetros e áreas. Universidade Cruzeiro do Sul - UNICSUL, São Paulo - 2006. Dissertação. 155 f. Mestrado no Ensino Profissional de Ciências e Matemática do Programa de Pós-Graduação, 2006.

BRASIL. Diretrizes Curriculares Nacionais para os Cursos de Matemática, Bacharelado e Licenciatura (2001). Disponível em: http://portal.mec.gov.br/cne/arquivos/pdf/CES13022.pdf. Acesso em: 13 abr. 2018.

BRASIL. Lei n. 9394 de 20 dezembro de 1996. Estabelece as Diretrizes e Bases da Educação Nacional. 5. ed. Brasília: Câmara dos Deputados, Coordenação Edições Câmara, 2010.

BRASIL. Secretaria de Educação Fundamental. Parâmetros curriculares nacionais: matemática. Brasília: MEC/SEF, 1997. 142p.

CARDIM, P. A. G. O professor como elo entre a escola e o estudante: como evitar a Evasão. In: COLOMBO, Sonia Simões; RODRIGUES, Gabriel Mario (orgs.). Desafios da gestão universitária contemporânea. Porto Alegre, RS: Artmed, 2011.

CURY, Helena Noronha; MOTTA, Carlos Eduardo Mathias. Histórias e Estórias da Matemática. In: CARVALHO, Luiz Mariano; CURY, Helena N.; MOURA, Carlos A. de; D'AMBROSIO, Ubiratan. Etnomatemática: elo entre as tradições e a modernidade. 2. ed. Belo Horizonte: Autêntica, 2002. 
D’AMBROSIO, Beatriz S. Como ensinar matemática hoje? Temas e Debates. SBEM. ano II. n. 2. Brasília. 1989. p. 15-19

FIORENTINI, Dario. Alguns modos de ver e conceber o ensino de matemática no Brasil. In: ZETETIKÉ. Campinas: UNICAMP, ano 3, n. 4, 1-36 p., 1995.

FONSECA, Maria da Conceição F. R. Educação matemática de jovens e adultos: especificidades, desafios e contribuições. 2. ed. Belo Horizonte: Autêntica, 2005.

FOSSA, John A.; GIRALDO, Victor (orgs). História e tecnologia no Ensino da matemática. v. 2. Rio de Janeiro: Editora Ciência Moderna, 2008.

FREIRE, Paulo. Educação e mudança. 11 ed. Rio de Janeiro: Paz e Terra, 1986.

LIMA NETO, Ananias Carneiro. Modelagem matemática como ambiente de aprendizagem na educação de jovens e adultos. In: Cadernos de Textos e Oficinas [da] IV Semana de Educação de Jovens e Adultos: Cenários da EJA: aprendizagem e relevância social nos contextos formais, não-formais e informais, de 22 e 23 de julho de 2013. Organização Selma dos Santos, Cristiano dos Santos. Feira de Santana: Universidade Estadual de Feira de Santana. Departamento de Educação. 2013, p. 140 -147.

MIGUEL, Antônio; MIORIM, Maria Ângela. História da matemática: propostas e desafios. 2. ed. Belo Horizonte: Autêntica, 2011. (Coleção Tendências em Educação Matemática).

Política nacional de extensão/ elaborado pelo Fórum de Pró-reitores de Extensão das Instituições de Educação Superior Públicas Brasileiras. Porto Alegre, RS: Gráfica da UFRGS, 2012.

SANTOS, Luiz Fernando C. A Etnomatemática na educação de jovens e adultos: cultura, crenças e valores no ensino de matemática. In: Cadernos de Textos e Oficinas [da] IV Semana de Educação de Jovens e Adultos: Cenários da EJA: aprendizagem e relevância social nos contextos formais, não-formais e informais, de 22 e 23 de julho de 2013. Organização Selma dos Santos, Cristiano dos Santos. Feira de Santana: Universidade Estadual de Feira de Santana. Departamento de Educação. 2013, p. 148-156.

SAVIANI, Dermeval. Sobre a natureza e especificidade da educação. In: SAVIANI, Dermeval. Pedagogia histórico-crítica: primeiras aproximações. 10. ed. rev. Campinas: Autores Associados, 2008. (Coleção educação contemporânea)

WEBER, Tamitsa Menezes, LOPES, Anemari Roesler Luersen Vieira. Educação matemática escolar: o fracasso do aluno ou do sistema? Curitiba: EDUCERE, 2013 